\title{
Mothers and the Phenomenology of the Memorable Photograph
}

\author{
Jonathan Yahalom, Duquesne University, Pittsburgh, USA \\ Email:yahalomj@duq.edu
}

\begin{abstract}
This article explores the phenomenology of mothers as they return to memorable photographs. ${ }^{i}$ It reviews research on three mothers who articulate the lived experience of photographs, and how such experience might reveal basic ontological aspects of motherhood. The phenomenology of a mother's memorable photographs discloses an aporia of human relationships that involves the connectedness she has with her children, and the awareness that her children have become separate individuals. These two themes - separateness and coexistence - are indissolubly at odds. Each constitutes a mother's potential lived experience of photographs as viewed in front of her. A concluding discussion reviews how each of these contradictory themes provides the necessary context for the other to arise, mutually presupposing the other.
\end{abstract}

\section{Introduction}

I once considered myself critical of the rituals of photography. From my perspective few photographers seemed to appreciate the object they were documenting. I found my opinion reflecting the words of Susan Sontag (1977) who wrote, "A way of certifying experience, taking photographs is always a way of refusing it - by limiting experience to a search for the photogenic, by converting experience into an image, a souvenir” (p. 9). But, my opinion has changed. My study on the lived experience mothers have of memorable photographs requires me to recognize photography does not necessarily cheapen experience. Memorable photographs disclose an aporia of human relationships situated between mutually dependent axes of coexistence and separateness. Contrary to my initial stance, photography might be said to enhance and highlight basic phenomenological features of the lived world. In this article, I undertake a study on mothers and the phenomenology of memorable photographs in order to understand how they may be revelatory of basic aspects of mothers' being in the world (ontology).

Earlier studies have investigated photography from other phenomenological vantage points. Roland Barthes (1981) in Camera Lucida phenomenologically studied the profound meaning that specific photographs have for him as a spectator. Jo Spence's (1986) Putting Myself in the Picture poignantly describes the experience of being photographed, standing vulnerable under the scrutiny of the camera. Marianne Hirsch's (1997) Family Frames helps unpack the significance of the operator who documents significant moments, bestowing subsequent generations with "post-memory" of the life that preceded them. Each of these works illuminates that photography is steeped with meaning and significantly affects our lived experience by modulating one's stance in the world. Given how much these pioneers recognize photography's importance in modern life, I wish to explore one specific way that photography is lived: mothers and photography-particularly, mothers who revisit memorable photographs and continue to take new ones. The following article seeks to provide phenomenological insight as to how this facet of photography is lived. 


\section{Method}

Like Roland Barthes (1981), I wanted "to learn at all costs what Photography was 'in itself'” (p. 3). In my experience with my own family and others, mothers seemed to take photographs more often, compared to other members. I came to recognize that I had to study a mother's experience of photography in order to appreciate what photography is. I recognized, along with Barthes, that no photograph has absolute meaning. A photograph is significant, not in an objective sense, but experientially, for the person situated within the network of meaning that surrounds the image. As Barthes (1981) writes: "Photography evades us" (p. 4). Barthes found that every photograph is contingent and meaningful to the extent that it is personal. In preparing my study, I realized that, in order to discover what photography is for mothers, I must first focus on what makes photographs meaningful.

I turn to the phenomenological method in order to investigate the lived experience of memorable photographs. Phenomenologically speaking, there is a difference between a discussion about the general meaning of photography and one centered on the meaning of a specific photograph. The Dutch phenomenologist, J.H. van den Berg (1987) explained: "Most essential in phenomenology is that the nature and the characteristics of human existence are to be found not by investigating man's subjectivity, but by studying and describing his world” (p. 8). Thus, to conduct my research, it would not help to ask a general question like, "Why is photography important to mothers?" Rather, I was required to stay grounded in the actual experience of why a particular photograph is important to the particular mother interviewed at a particular time.

Phenomenology, as a method, derives from the work of Edmund Husserl (1970) who is known for his motto, "We must go back to the things themselves" (p. 252). He argued that every science must be situated within the primary experience individuals have with the world. Before anything else, investigators must understand the unique experience of the object. Giorgi (1970) was one of the first to rigorously apply phenomenology to contemporary psychological research. He argued that the field of psychology must be grounded within a "human science" framework, and that phenomenology is the best approach. Fischer (1974), Wertz (1984), and Churchill (2001) demonstrate that phenomenology is a viable methodology that fosters a perspective neglected by other standard modes of research. Their critique directly pertains to the topic of my study. One approaches the phenomenon incompletely by investigating the nature of mothers' memorable photographs and overlooking mothers' lived experience - the memorableness - of them. By attempting to provide an overall "objective" theory of photography, traditional research methodologies fall short. They miss the essence of mothers' experience of memorable photographs, distracting us with generalized findings that have little to do with specific lived experience. The phenomenological method is empowering precisely because it provides a way to articulate the overall meanings (Giorgi (1985) calls them "meaning units" (p. 10)) of experience while not abstracting them from the structural and dynamic relationship of self and world.

The phenomenological method requires that researchers attempt to put aside preestablished knowledge (first-personal or theoretical) in order to focus on the concrete way memorable photographs are experienced in participants' lives. Following Giorgi (2009), who argues that the phenomenological method aims at knowledge through individual examples, I collaborated with three mothers. Each mother was interviewed while looking at memorable photographs of their children, that is, photographs attributed with more significance when compared to others. I collected descriptions of how specific photographs were meaningful, and took an audio recording of each interview, which I later transcribed. After, I reflected on each mother's experience of looking at memorable photographs, I differentiated their descriptions into meaning units by identifying different phenomenological themes and 
subsequently reflected on the psychological significance of each.

However, it is misleading to claim that my approach strictly adhered to the phenomenological method. In order to clarify the psychological structures of experiencing memorable photographs, I mobilized phenomenological themes articulated earlier by writers like Minkowski (1970), Heidegger (1971), Barthes (1981), Hirsch (1997), and other pioneers. In this regard, it is more accurate to describe my method as "hermeneuticalphenomenological” (Van Manen, 1997). Recent theoretical arguments caution against this approach. Kakkori (2009) argues that this method is contradictory because hermeneutics and phenomenology are incompatible. This argument is based on the assumption that phenomenology aims to discover universal meanings, whereas hermeneutics is limited to culturally specific ones. Yet, Kakkori's critique neglects foundational work in phenomenology that relies on hermeneutic tools. Heidegger (1962) explicitly adopted hermeneutic phenomenology as his primary method and Gadamer (1976) argued that the hermeneutic dimension is invariably required in the act of putting experience into language. Moreover, we now recognize that the experience of photographs is a culturally specific phenomenon (Sontag, 1977). So, it makes little sense to limit oneself to concrete description and neglect the rich hermeneutic literature that articulates and clarifies our cultural landscape. By appropriating hermeneutic tools, I am able to further reflect and clarify the structures inherent to a mother's experience of memorable photographs.

My research began by interviewing two mothers in my community. In what follows, I use pseudonyms to protect the confidentiality of my participants. My first participant was a mother whom I will call "Samantha." At the time of my interview, Samantha was in her early 30s and joyfully articulated the meaning of photographs of her month-old first child. After this, I collaborated with another mother, “Jessica.” Jessica was in her mid-30s and described the experience of looking at family photo albums she'd created of her two young boys. Like all my participants, Jessica's descriptions were rich. She said while introducing her photo album, "These photographs... are amazing to me because [I see] this little body I knew from the beginning that was [once] inside... And yet there's this physiology that's still there. A certain shape of a hand or the way his belly is still the same, but now he's five and not two anymore.” In gaining a vivid description of experiences like the one Jessica shared, I was on my way to appreciating the phenomenology of photography.

Although each interview provided rich insight into a mother's experience of looking at memorable photographs, something seemed suspect. I had an uncanny suspicion that my story as a researcher paralleled the narrative in Ruth Behar's (1996) essay "Death and Memory.” In this essay, Behar is an anthropologist who describes traveling abroad to study Spanish death customs while she simultaneously lacks the courage to confront the death of her own grandfather. I wondered whether I was like Behar, interviewing other mothers because I did not want to interview my own. I recognized a need to identify and explore my own assumptions about the phenomenon, and finally confronted my resistance upon reading St. Pierre (1997) who made me realize that studying the meaning articulated by another person "necessarily examines the construction of my own subjectivity" (p. 177). In asking mothers to describe the experience of looking at memorable photographs of their children, I inevitably questioned the feelings my mother had toward photographs of me. So, I decided to interview my mom. Over a Skype video-call that highlighted the distance between Pittsburgh and Los Angeles, my mom displayed the iconic photographs of my childhood while I asked her to articulate her experience of them now. Interviewing one's mother is not easy but, as I will describe, the experience has significantly informed conclusions drawn in this study.

Although all my interviews were unique, I asked each participant the same set of broad questions while the participants were looking at specific photographs of their families: "What is it like for you to experience this photograph?" "Can you explain the photograph's 
significance now?" "What do you currently remember about the image depicted?" The physicality of each photo was less important than a mother's experience. By investigating the lived experience of memorable photographs now, my questions attempted to avoid approaching the photographic image as representational object. Yet, however similar my questions were, each mother gave slightly different answers. I suspect this is partly due to the way I intentionally designed this study to interview three mothers at different stages of motherhood. Samantha, the newest mother, talked about the meaning of photographing her one-month-old girl. Jessica was a mother whose two boys (ages 3 and 5) appreciated family photographs and expressed what it is like to share photographs together. Finally, my mother represented what it is like to witness a child mature into adulthood, and the meaning photographs serve at this period in her maternity. Each of my participants' accounts demonstrates how photographs powerfully disclose an aporia in maternal (and perhaps more generally human) relationships. In what follows, I will explore two central themes that structure a mother's experience of memorable photographs.

\section{Separation: Disclosing the Loss of Maternal Proximity}

A mother's experience of photographs discloses the reality that her children have become separate individuals. This engenders powerful experiences of reminiscence and, ultimately, loss.

I begin by considering Samantha, who reflected on her experience of photographs of her first newborn. Even though Samantha has recently become a mother, looking at photographs of her baby signifies that her daughter will not remain the same, and that they will inevitably grow apart. Describing the experience of a photograph taken from the day of her daughter's birth, Samantha said, "From when I brought her home, you know, it's gone forever. She's changed from the day she was born till now." Implicit in Samantha's experience of this photograph is the recognition that her memory is different from the present, and that the present will continue to be different from the future. My mother expressed similar sentiments when remembering why she chose to document specific moments in our family life. She said, "Well, just to remember it by. I knew all the years go by so fast, to look back and remember these different times in your life growing up... so you would have memories of growing up." In a significant way, photographs signify that moments in a mother's life are literally "gone forever." For Samantha, this pivotal moment is represented in the act of bringing her newborn home. To bring someone (or something) home signifies a gesture of appropriation. Samantha introduces her newborn into the narrative she had created prior to becoming a mother. Yet, unlike introducing an object, the infant Samantha introduces will inevitably grow up.

According to Gilles Deleuze (2004), this is the basic structure of temporality: all things that occur in the present eventually recede into the past. Yet, the present moment does not pass out of existence simply because another moment arises. Rather, Deleuze argues, each moment has two temporal dimensions, a present and a past, at the same time. Pastness is an element of the present moment, enabling us to anticipate time's fleeting nature. This accounts for Samantha's experience of her photograph. Through it, she experiences the origins of her new maternal relationship, which simultaneously marks her sense of loss. In this act, Samantha recognizes that change is an inevitable feature of the daughter she has welcomed into her life.

Jessica expressed a similar experience of loss upon looking at an early photograph of her eldest son. She said:

It’s a pretty emotional experience for me, actually. Because, my God, he’s so changed 
and there's so much growth and he is developing and becoming more and more, you know, his own person in this world... Notice that there is a thing about the closeness. I still feel that I can look at these early shots and think, "He's his own person in the world here," and we were much closer at a bodily level at this point when he was a year old. [Now] he doesn't need me to change his diapers. He's independent in a way...

The temporal continuum that Jessica experiences in looking at her five year old son as an infant serves to remind her of how he once was physically a part of her own body. Jessica's tactile experience expresses a common element of the visual realm. In Textures of Light Cathryn Vasseleu (1998) argues that tactility is an essential aspect of visual sensation, that light necessarily implicates touch. As Jessica sees the photograph of her son, she describes the emotional experience of continuing to feel his presence. This felt sense of the photograph is one of loss. Distinct from the historical moment in the photograph, Jessica's son has increasingly become his own person, and, as a consequence, she feels their closeness has gone.

The way photographs signify loss is a theme articulated by many phenomenological investigations on photography. Barthes (1981) discovered that the noeme of photography is ça a été - that has been. The phenomenology of a photograph is a referent that is both present (as image in the photo) and absent (as the object was once there, but is now no longer). Barthes was partly responding to Sontag (1977) who wrote, "All photographs are memento mori. To take a photograph is to participate in another person's (or thing's) mortality, vulnerability, and mutability. Precisely by slicing out this moment and freezing it, all photographs testify to time's relentless melt” (p. 15). Barthes concludes his study by equating photography with death: the represented object exists, but only in context to its nonexistence. While the mothers I interviewed recall the events from early moments of their children's lives, they also recognize that their memory signifies loss. Even for Samantha, her experience of photographs already expresses nostalgia. This, perhaps, is the only way to make sense of Samantha's experience of events from her maternity being "gone forever."

Implied in recognition of loss is a mother's desire to preserve significant family moments. While looking at photographs, the mothers I interviewed expressed a sincere appreciation for their earlier efforts to document moments of their children's lives. In this regard, the experience of memorable photographs reminds mothers that they ought to continue taking photographs so as to protect against future loss. They anticipate that memory is liable to change, and turn to photography to ensure against future loss. Jessica articulated this sentiment through a metaphor that harkens to the process of developing film. As she looked at a memorable photograph of her second child, Jessica described a sense of appreciation for choosing to document memorable moments. For Jessica, looking at memorable photographs is a reminder of the process of taking them. She explained how, after film is developed, it must be "fixed" in chemicals to prevent it from over-developing. The process of fixing stabilizes an image so that, once removed from the dark room, it will not continue absorbing light and turn black. She said:

The photographs fix the memory... So it really keeps the image, it holds it. It keeps it in time in a way. It keeps it physically there. It fixes it. So it's like, whereas otherwise that memory might continue to develop on its own, in its own organic way according to time. Photographs kind of keep it.

Jessica's sentiment reflects the profound injunction mothers experience when remembering significant moments through photographs. She recognized that memory alone is imperfect 
and that we need an object to retain memory. Jessica's sentiments echo Walter Benjamin (1968) who wrote, "Every image of the past that is not recognized by the present as one of its own concerns threatens to disappear irretrievably" (p. 255). Once more, we witness a mother's deep awareness of loss; that the moments that she desires to "fix" in time are moments that are impossible to absolutely preserve.

Jessica's experience is significant for other reasons, considering that she was describing photographs in their immediacy. In her experience of the memories evinced by photographs, Jessica indicates that she has succeeded in "fixing" or preserving her memories. They are "fixed" in a specific way. Like any piece of art, the experience of photographs does not exist objectively. A specific photograph can be meaningless to one individual, and substantive to another. In Davey's (1999) hermeneutic investigation on visual aesthetics, he argues that artwork "does not re-present subject matter but extends and alters their being” (p. 4). Considering Gadamer's (1976) argument that the hermeneutic dimension is required in talking about experience, the experience of art (including the family photograph) is a hermeneutic act that transforms the temporal limitations of the object and, in so doing, transforms experience itself. An object depicted by a photograph is proof - not of the object's existence - but that it once was. It is too simple to claim that photography is similar to language. Photographs communicate loss, but unlike language photographs authenticate. As Barthes (1981) wrote, "every photo is a certificate of presence whose existence is preceded by absence" (p. 87).

In other descriptions of memorable photographs, Jessica provided more insight into this experience. Jessica paused to reflect on her experience while looking at a photograph depicting her second son as an infant sleeping on her abdomen. In her description, she said that this photograph "held her memory" and I asked her to explain. She responded:

This photograph is one dimensional in a way. It's the surface, but yet it also evokes what everything else that's there you can't necessarily hold. But you can't hold, you can only hold one part of it. And that one part is what the camera can get. But you can't hold every other part of it that it evokes - You know it's there.

As re-creations of moments in her history, Jessica shows how a photograph is never merely the image depicted. Jessica' description illuminates her awareness that the photograph is only an image, while transcending to something beyond it. Studying the phenomenology of photography, Niedbering (2011) reminds us that a photograph is not an un-mediated visual phenomenon precisely because our experience of memorable photographs is of something not visible in the image. What we experience is not the image of the photograph, but rather the response it engenders. Jessica is aware that everyone sees a "one dimensional" image. Yet, for her, this memorable photograph fosters a multidimensional experience. The essential part of the photograph is what it "evokes," which Jessica is certain is present despite merely being intimated by the image.

Photographs evoke what Barthes (1981) calls the "punctum," an intense experience of presence that is not directly contained in the photographic image. The punctum is the jarring experience, the personally touching detail that fosters intimacy with the photographic image. Objectively speaking, the punctum does not exist "in" the photograph, but is rather constitutive of our experience with it. Martin Heidegger (1971) was the first to observe the way that things are a type of "gathering" that recall an entire world of meaning. Proust's literary description of the madeleine - written exactly 100 years ago - is another example. Proust was able to recall a whole world of sensations, feelings, people, etc. - just upon tasting the treat that was iconic of his youth. But we need not turn to literature to indicate something so fundamental. Just like the madeleine, memorable photographs gather and 
remind us of the circumstances surrounding the event. Through them, the past is experienced as active and alive: we hear clamor, we feel the messiness of something that is no longer. In a sense, we re-live any given memory as something that constitutes us in the present.

To this end, my mother described the experience while looking at one of her favorite photographs. Her description also transcended the scope of the photographic image. She began to recall her memory of the event:

I don't know if it was the first day, but it was, you know, the beginning of when I returned to work. So I couldn't wait to get back because I only tried to go while you took a nap... And you were already up and it was in the front yard and you ran out... and I grabbed you up and picked you up, and I was so happy to see you. That was a great memory.

What is experienced in memorable photographs is precisely what they do not contain: memory. Eugène Minkowski (1970), who investigated the phenomenology of memory, articulated the multidimensional experience of a one-dimensional object. He wrote, "The phenomena of memory are really complicated and become singularly rich... Memory cannot be reduced merely to an image or a representation of a fact" (p. 155). This is furthered through Paul Ricoeur's notion of "worldliness.” According to Paul Ricoeur (2004), the things we remember constitute a horizon beyond the direct image associated to it. He writes:

One does not simply remember oneself, seeing, experiencing, learning; rather one recalls the situations in the world in which one has seen, experienced learned. These situations imply one's own body and the bodies of others, lived space, and, finally, the horizon of the world and worlds, within which something has occurred. (p. 36)

My mother's description of what her photograph "evokes" is an entire world that situates the photographic image. The memorable photograph provokes her return to the world that is jarringly lost in reality, yet existent in memory.

What is lost is mediated by what has been gained - namely, the manner in which a mother's child develops into a distinct individual. Memories fostered by photographs are memories of reminiscence and feelings of loss. In Samantha's words, what is "gone forever" is the period of a mother's life where children are less distinct than they are now. The phenomenology of a mother's memorable photographs is, then, partly the way in which she experiences her children's individuality. This experience is contextualized by a mother's current recognition that time has passed and her children have matured. As I will discuss in the subsequent section, a mother's experience of separation appears while also experiencing the opposite.

\section{Coexistence: Rediscovering the Maternal Bond}

However significant the dimension of separateness is, my research also revealed a contrary feature in a mother's phenomenology of memorable photographs. A mother's experience of memorable photographs equally signifies that she coexists with her children, that they are never wholly separate. The phenomenology of memorable photographs discloses that mother and child are contingently situated. This experience engenders the recognition that a mother's maternity does not abruptly expire but rather continually constitutes her self-experience.

One of the themes articulated by the mothers I interviewed is that photographs are meaningful in providing a glimpse of the mother's worldview. For Samantha, whose family 
lives in another state, sending pictures of her newborn daughter is an important gesture to establish connectedness. Looking down at her sleeping baby, Samantha explained, "All of her family lives really far away and people are really eager to see just day to day changes, updates..." Samantha explained that photographs respond to her own mother's expectation to remain connected despite living so far away. She said:

There's a lot of pressure from her. So no matter how many pictures she gets there's not enough. No matter how many stories she hears it's not enough. So it's a little stressful. But yeah, it’s really important. My mom's just completely in love with her, as we're all.

Samantha's description of her mother matches her own understanding as a new mother. To express love, both mother and grandmother seek to feel connected with the new member of their family. Samantha's comment shows how photographs are significant-in part, because they help foster greater connectedness. In this regard, the contemporary experience of photography is markedly different than a few decades ago. With the development of smartphones and mediums to exchange digital photography, photographs respond to even greater demands for connectivity. More relevant than ever before is Barthes' (1981) observation that "the Photograph is never anything but an antiphon of 'Look"' (p. 5). Resembling a choreographed dance, one sees a friend's photograph, and is expected to respond by showing her own. By now, even the most quotidian experiences are shared through photography.

Photography fosters connection, and significantly constitutes a mother's relationship with her children. As Samantha looked at a photograph of her daughter coming home for the first time, she described how she anticipates that this particular image will be important for her daughter. She said, "It will help her tell stories about herself. I think that's the good narrative for kids to hear. Stories about what they were like when they were younger. And they sort of repeat it. And I think it even gives them a sense of security." Samantha's experience of looking at this memorable photograph engenders a specific interpretation of the meaning of her experience - namely, that the photograph will soon comfort her daughter. For Samantha, this memorable photograph is important because it tells a story that she anticipates her daughter will one day adopt as her own. Samantha anticipates her daughter will recognize that she was not born alone, but rather into a world steeped with love. Samantha is constructing a life story in pictures that she hopes her daughter will take up as her own. Ricoeur (2004) describes Samantha's sentiment as a "testimony" that is endowed to one person by another from the past. He writes that such memories "allow us to affirm that 'in reality, we are never alone’” (p. 120-121). For Samantha's daughter, knowledge of her mother's love helps create greater awareness of family ties and, ultimately, comfort in the larger world. This fosters understanding in a larger network of individual ties. Eva Simms (2008) develops this idea further by pointing to the way in which collective memory "promises an easier, less threatening future" (p. 157). The phenomenological tradition articulates what Samantha's experience reveals, namely, a mother's experience of photographs is a reminder of the maternal bond she shares - and will continue to share - with her children.

Like Samantha, my mother expressed that specific photographs are memorable for their anticipated importance in the future. As her children have grown, she now focuses on their intergenerational significance. She said of her experience looking at one family photograph, "Well, you would show your wives or kids one day, [maybe even] your grandkids." Her answer was a simple way to point to the powerful notion that my future will involve my past, and my horizon will be enlarged and deepened just as photographs once welcomed me to my 
larger family network. And so, as much as photographs serve to introduce a hospitable world for young children, they also serve the future a mother anticipates for her children. Hirsch (1997) explains that this anticipation is part of the larger phenomenology of family photographs. Her analysis is influenced by Barthes' (1981) notion of the photograph's "imagetext" (the experience of the text of narrative imbedded in the image). Hirsch develops this notion further, arguing that such experiences instill viewers with "postmemory." Unlike standard notion of memory, postmemory is mediated and distinguished by generational distance and personal connection. As Spence and Holland (1991) write, "Family photography can operate at this junction between personal memory and social history... Our memory is never fully 'ours,' nor are the pictures ever unmediated representations of our past” (pp. 1314). Postmemory characterizes the way in which mothers anticipate that the family narrative preceding their children (and children's children) will nevertheless be remembered.

In addition to the way that a mother's experience is future-oriented, a memorable photograph also signifies that she coexists with her children now. This is to say, photographs disclose that the maternal-child bond continues to endure, despite recognition that children grow up. Recalling that my grandmother had lost her family photographs after surviving the Holocaust, I asked my mother what it would be like not to possess her most memorable ones:

Me: How would you feel if you lost all of these pictures?

Mom: I'd be devastated... Because these are ... our lives... glued together.

Me: Explain it more.

Mom: Well, this is what the two of you [brothers]... how the two of you grew up and I helped you through that phase... and... how I raised you... so to me, it’s my life.

My mother's response signifies the way in which photographs are part of a deep connection with her children. In examining them, my mother experiences her life "glued together" with my brother and me. On the surface, her photographs document a history of being coconstituted with her children. Yet, insofar as the experience of photographs evokes a punctum, the intense feeling of presence, my mother experiences this moment in her history now. She understands herself as living her history, as co-existing with her children just as the image depicts her stance in the past. This is the subtle "beyond" of her experience of the photographic image.

My mother's last statement suggests that she experiences her life (at least in part) as constituted by the history of her maternity. These memorable events are the temporal valences upon which my mother has built her life. Minkowski (1970) writes that the past "does not unfold before our eyes in successive stages, each one having it's value independent of the other; on the contrary, it turns back upon itself, condenses to the maximum" (p. 157). For my mother, the past seems to be condensed in the punctum of her experience of photographs now. This history also indicates that she experiences time in a particular way. Rather than conceptualizing time objectively, my mother experiences it by the sequences of events remembered by her family photographs. In this vein, time is significant for the memorable moments evoked by the photographic image. This way of living time is also characteristic of how children experience temporality. Simms (2008) explains how children experience time through the sequence of events that are most important. (Most children understand time by comparing and contextualizing events based on what is important in their day. For example, they might experience that eating breakfast comes before Dad leaves to work; naptime occurs after returning home from school; and so on.) While we are quick to discard this structure of temporality as immature, Simms maintains that it is the foundation for all subsequent adult experiences. A sense of lived time, she writes, "is with us as long as we live in a body and perceive in the world, and it remains the pre-reflective foundation for 
mature thought” (p. 136). As such, a mother's photographs signify the moments around which she understands temporality.

Time is experienced through the specific connection mothers share with their children. My mother's conception of her life is woven with how she recalls raising my brother and me. Perhaps this is why the punctum a mother experiences evokes such powerful memories. As Ricoeur (2004) explores, memory is never an isolated experience but done in context of other people. He writes:

One does not remember alone... Childhood memories are an excellent reference in this regard. They take place in socially marked places: the garden, the house, the basement... By this we understand that the social framework ceases to be simply an objective notion and becomes a dimension inherent in the work of recollection. (pp. 121-122)

The notion of collective memory stands at odds with what Ricoeur calls the "sensualist thesis" of memory as a first-person phenomenon. While one might initially interpret memories invoked by photographs as private, Ricoeur helps clarify that they are inescapably social. A mother's experience of memorable photographs is essentially an experience of coexisting with her children, despite recognition the reality that her children have grown up.

A mother's experience of photographs is constituted by the indissoluble connection she has with her children. Despite recognition that children grow physically distant, the punctum of memorable photographs situates mothers in moments that exemplify their maternal bond. In my mother's words, memorable photographs reconstitute "our lives glued together." The phenomenology of a mother's memorable photographs partly concerns how mothers experience memory and time interwoven with their children. In this regard, the experience of a memorable photograph might be testimony to a sense of coexistence and to the conviction that a mother upholds her maternal role despite passage of time.

\section{The Impossibility of Separation and Coexistence}

While they simultaneously indicate awareness that their children have become separate individuals, photographs signify the indissoluble connectedness mothers have with their children. The two themes - separateness and coexistence - are indissolubly at odds, while each constitutes a significant aspect of a mother's phenomenological experience of memorable photographs. The mothers interviewed experienced photographs as reminders of her children's growing independence, engendering a sense of reminiscence and loss. They also experienced photographs as testimony to her irrefutable maternal role, co-constituted with her children. Both separateness and coexistence are ideals: they seem to constitute a mother's experience; yet, they are impossibilities in the absolute sense. A mother does not experience absolute harmony with her children; nor do her photographs signify that she has absolutely lost them. ${ }^{2 i i}$

This conclusion resonates with Jay Lampert's (2012) investigations on simultaneity and delay. He finds that each temporal dimension presupposes the other as opposite. Without the existence of one, the other is impossible. Simultaneity is only comprehendible so long as we have a sense of delay, and vice versa. Analogous to his argument, coexistence seems to situate a mother's reminiscence, and recognition of separateness in the same way seems to situate a mother's sense of connection. Presupposed in a mother's bond with her children is the recognition that she is separated from them. In this vein, the way this article suggests to distinguish two phenomenological themes is contrived and ultimately distorts the reality of a 
mother's lived experience. Both themes constitute significant aspects of her experience of memorable photographs, despite their deep underlying tension. Memorable photographs might disclose an aporia of human relationships situated between these mutually dependent axes.

\section{Future Research}

It is beyond the scope of this article to generalize a mother's experience of memorable photographs to the larger population, or to the digital sphere. I cannot confirm that the tourist who reviews his photographs on Facebook and other online social media has a similar experience as the mothers I interviewed. As the use of photography has congruently increased with technological advancements, one could argue that photographs are a means to protest feeling more isolated (Turkle, 2011). For this reason, I conclude to encourage reflection on photography in the digital era. The phenomenological experience of digital photographs (experienced on cell phones, social media, and other platforms) remains unexplored. Since all of my interviews involved printed photographs, subsequent research should investigate phenomenology of a mother's experience of digital photographs.

\section{References}

Barthes, R. (1981). Camera lucida: Reflections on photography (R. Howard, Trans.). New York: Hill and Wang.

Behar, R. (1996). The vulnerable observer. Boston: Beacon Press.

Benjamin, W. (1968). Illuminations (J. Zohn, Trans.). New York: Schocken Books.

Churchill, S., \& Wertz, F. (2001). An introduction to phenomenological research in psychology. In K. Schneider (Ed.), The handbook of humanistic psychology. Thousand Oaks: Sage Publications.

Davey, N. (1999). The hermeneutics of seeing. In I. Heywood, \& B. Sandywell (Eds.), Interpreting visual culture: Explorations in the hermeneutics of the visual (pp. 3-29). New York: Routledge.

Deleuze, G. (2004). Difference and repetition (P. Patton, Trans.). New York: Continuum International Publishing.

Fischer, C. (1974). On the phenomenological mode of researching "being anxious.” Journal of Phenomenological Psychology, 4(2), 405-423.

Gadamer, H. G. (1976). Philosophical hermeneutics, (David E. Linge, Trans.), Berkeley. Berkeley University Press.

Giorgi, A. (1970). Psychology as a human science: A phenomenologically based approach. New York: Harper \& Row.

Giorgi, A. (1985). Phenomenology and psychological research. Pittsburgh: Duquesne. 
Giorgi, A. (2009). The descriptive phenomenological method in psychology: A modified Husserlian approach. Pittsburgh: Duquesne.

Heidegger, M. (1962). Being and time (J. Macquarrie and E. Robinson, Trans.). New York: Harper \& Row.

Heidegger, M. (1971). The thing. In Poetry, language, thought (J. Hofstadter, Trans.). New York: Harper Row.

Hirsch, M. (1997). Family frames: Photography, narrative, and postmemory. Cambridge: Harvard University Press.

Hussurl, E. (1970). Logical investigations (J. Findlay Trans.). New York: Humanities Press.

Kakkori, L. (2009). Hermeneutics and phenomenology problems when applying hermeneutic phenomenological method in educational qualitative research. Paideusis, 18(2), 19-27.

Lampert, J. (2012). Simultaneity and delay: A dialectical theory of staggered time. New York: Continuum.

Minkowski, E. (1970). Lived time (P. Metzel, Trans.). Evanstown: Northwestern University Press.

Nieberding, W. (2011). Photography, phenomenology and sight: Toward an understanding of photography through the discourse of vision. (Dissertation, Ohio State University).

Ricoeur, P. (2004). Memory, history, forgetting (A. Blamey, F. Pellauer, Trans.). Chicago: University of Chicago Press.

Simms, E. (2008). The child in the world. Detroit: Wayne State University Press.

Sontag, S. (1977). On photography. New York: Dell Publishing Co.

Spence, J. (1986). Putting myself in the picture: a political, personal, and photographic autobiography. London: Camden Press.

Spence, J \& Holland, P. (1991). Family snaps: The meaning of domestic photography. London: Virago.

St. Pierre, E. (1997). Methodology in the fold and the erruption of transgressive data. In Qualitative Studies in Education, 10(2), 175.

Turkle, S. (2011). Alone together: Why we expect more from technology and less from each other. New York: Basic Books.

van den Berg, J. H. (1987). The rise and fall of the medical model in psychiatry. The Silverman Conference. Duquesne University, Pittsburgh, PA.

Van Manen, M. (1997). From meaning to method. Qualitative Health Research, 7(3), 345- 
369.

Vasseleu, C. (1999). Textures of light: Vision and touch in Irigaray, Levinas, and MerleauPonty. New York: Routledge.

Wertz, F. J. (1984). Procedures in phenomenological research and the question of validity. In C. Aanstoos (Ed.), Exploring the lived world. Carrollton GA: West Georgia College Press.

\footnotetext{
i The Duquesne University IRB approved the research conducted in this article (Protocol \#11-27). The author would like to thank Eva Simms, Patrick Howard, and two anonymous reviewers for helpful feedback while preparing this article. This article is indebted to the three mothers who participated in this research.

ii Although none of the mothers interviewed mentioned trauma, I suspect that even mothers who have lost their children to death or other circumstances still experience their children's presence through memorable photographs.
} 